\title{
Sleep Quality Improvement of Benign Prostate Hyperplasia Patients After Transuretral Resection of Prostate
}

\author{
Alice Agustine ${ }^{1}$, Marta Hendry ${ }^{1 *}$ \\ ${ }^{1}$ Department of Surgery, Faculty of Medicine, Universitas Sriwijaya, Indonesia \\ *Correspondence Author Email: martahendry@gmail.com
}

\begin{abstract}
Introduction. Nocturia is lower urinary tract symptoms on benign prostat hyperplasia patients that made him asleep at night to urinate. This condition impacted on many level of patient life, which are quality of life, quality of sleep, daytime function, morbidity and mortality and nocturia has the biggest impact on patient sleep quality.

Methods. This is an observational study including 30 patient of benign prostat hyperplasia undergoing transurethral resection of the prostate as research subjects. All patient were assessed using the Pittsburgh sleep quality index and international prostate symptom score at baseline and 2 month after transuretral resection of the prostate

Results. A total 23 patients $(76,7 \%)$ had a sleep disorder as a score of 5 or more on Pittsburgh sleep quality index score. After the transurethral resection of the prostate, pittsburgh sleep quality index score of 12 patient have decreased (less than 5) and 11 others with persistent sleep disorder. Pittsburgh sleep quality index significantly decreased after transurethral resection of the prostate from $\pm 9,36$ to $\pm 5,03$ ( $\mathrm{p}$-value 0,000 ). Nocturia also significantly decreased after transuretral resection of the prostate from $\pm 3,46$ to $\pm 2,40$ (P value 0,003 ). Lower urinary track symptoms in this patient also getting better after surgery. The international prostat symtoms score decreased after transurethral resection of the prostat from $\pm 21,80$ to $\pm 7,67$ with $P$ value 0,000

Conclusion. Transuretral resection of prostate improves sleep quality dan decreased lower urinary track symptoms in benign prostate hypertrophy patients.
\end{abstract}




\section{STS SRIWIJAYAJOURNAB OFEURGERY}

Key words : sleep quality, nocturia, transurethral resection of the prostate, benign prostate hyperplasia

\section{Introduction}

Nocturia, one of the symptoms of voiding disorders is the main cause of the patient's awakening repeatedly in the nights of micturition. The prevalence of nocturia increases with age and nocturia has the greatest influence on a patient's sleep quality. The influence of nocturia on a patient's life has been divided into several different levels, namely influencing the quality of life, on the quality of sleep, on the functions of daily life, on morbidity and even mortality. Nocturia is defined by the International Continuing Society as waking up at night once or more to urinate. Patients who wake up more than once a night to urinate can feel uncomfortable and tired. Jensen et al reported that as many as $25 \%$ of the falls experienced by parents at night and as many as $25 \%$ caused by patients waking to urinate ${ }^{1-7}$.

In patients with lower urinary tract symptoms, nocturia increases with age. A study by Lee found that patients with nocturia show poor sleep quality and nocturia have a great influence on the sleep quality of patients with benign prostate hyperplasia (BPH). The percentage of nocturia is $16 \%$ in men aged $40-49$ years, $60 \%$ at age $70-79 \%$ and is mostly caused by BPH. There were no significant differences in patients with nocturia in age, prostate volume, prostate spesific antigen (PSA), Qmax and postvoid residual (PVR) between patients with or without nocturia. Total International prostate symptom score (IPSS) and quality of life (QOL) index of patients with nocturia are higher than patients without nocturia. Patients with nocturia have a higher Pittsburgh sleep quality index (PSQI) and a percentage of sleep disorders. Nocturia has a higher influence on LUTS patients. In older people with nocturia, sleep quality is associated with lower urinary tract function. Good sleep quality is subjectively associated with longer slow wave sleep (SWS) time and subjective good sleep quality is associated with higher urinary flow rates and lower nocturnal urinary volumes ${ }^{8-10}$.

Sleep quality was assessed using the Pittsburgh sleep quality index (PSQI) score, whose a questionnaire to check someone's sleep quality in a month. This scoring is increasingly widely used because researchers can use it for research related to sleep disorders, depression and bipolar 


\section{SISS SRIWIJAYA JOURNAB OFEURGERY}

disorder. PSQI consists of 19 questions that form 7 assessment components, including: subjective sleep quality, sleep latency, sleep duration, daily sleep efficiency, sleep disturbances, use of sleeping pills, and dysfunction of activities during the day. The total score of the seven components produces a global score that is used to assess sleep quality or not with a cut off point $5 .{ }^{11-13}$

Shunichi Namiki examined IPSS scores of BPH patients before and after TURP surgery with the results that the average total IPSS and QOL scores increased progressively with improvement over time. The mean values of some components increased significantly after TURP surgery, but no significant changes occurred in the symptoms of nocturia before and after surgery, with the conclusion that the ratio of improvement of nocturia to 7 symptoms of LUTS was the lowest $^{14}$. Likewise, Luitel Gupat examined the results of post TURP surgery after 3 months showing a significant decrease in IPSS scores, symptoms of voiding that were better than storage symptoms but storage symptoms were unlikely to return to normal ${ }^{15}$.

Naoki Wada's research in 2012 stated that nocturia is one of the most annoying symptoms of LUTS for patients and is the most difficult to treat because the disease that causes nocturia varies from urological conditions to non-urological conditions. In 38\% of patients with LUTS, the prevalence of sleep disorder decreased to $24 \%$ after TURP and this was correlated with age. Naoki Wada research results showed that the total IPSS value dropped significantly after TURP surgery, from \pm 18.1 to $\pm 5.9(\mathrm{p}$-value $<0.001)$ and nocturia points also dropped significantly from \pm 3.0 to \pm 1.9 ( $\mathrm{P}$ - value $<0.001)$, but the improvement of nocturia is not in line with the improvement of sleep quality where of the 20 patients who experienced sleep disorders before TURP surgery, only 4 people experienced progress, while 16 people $(80 \%)$ others experienced persistent sleep disorders ( PSQI score \pm 5.4 to \pm 4.3 , P-value 0.11). According to Naoki Wada's research, the improvement of nocturia was not related to the improvement in sleep quality of BPH patients after surgery ${ }^{1}$.

From the various studies above it was concluded that TURP significantly reduced IPSS and nocturia scores after surgery, but there have been no studies that reported sleep quality associated with improved nocturia by TURP in Indonesia. Therefore this study intends to explore the effectiveness of TURP on the improvement of nocturia (symptoms of LUTS) assessed by IPSS and sleep quality. 


\section{STS SRIWIJAYAJOURNAB OFEURGERY}

\section{Methods}

This research was an observational study. Study participants consisted of $30 \mathrm{BPH}$ patients who were going to have a TURP operation and who had done TURP operations in the urology sub-section of RSMH Palembang that met the inclusion and exclusion criteria. Criteria for inclusion of patients with a diagnosis of suspected BPH and TURP surgery will be done, patients suspected of BPH with ages between 50 to 80 years, patients are willing to follow the study and sign informed consent. Exclusion criteria were BPH patients who had undergone TURP surgery before, patients with anatomic pathology results not benign prostatic hyperplasia and patients with comorbid heart failure, neurogenic bladder and kidney failure.

Evaluation of the improvement of nocturia used IPSS. Symptoms are categorized as mild if the score is 1-7, categorized as moderate if the score is 8-19 and severe if the score is 2029. Assessment of sleep quality was assessed using PQSI. If a score of $\leq 5$, then it would be categorized as good sleep quality and if score $\geq 5$ was categorized as poor sleep quality. Data analysis of the results of the study was carried out using SPSS version 24. Data was presented in the form of a frequency distribution narrative table. Next, bivariate analysis was performed between groups with paired-T test for groups before the TURP action and after the TURP action.

\section{Results}

In IPSS before TURP surgery, most BPH patients had a heavy IPSS score of 18 people (60\%), a moderate IPSS of 10 people (33.3\%) and only 2 people with a mild IPSS. In the condition after the surgery, there were many clinical improvements of patients assessed by IPSS, most patients experienced improvement into the mild category of 17 people $(56.7 \%)$, the moderate category of 12 people $(40.0 \%)$ and only 1 person who did not experience improvement clinical symptoms that are persistent in the severe category. Twenty three BPH patients had poor sleep quality and 7 patients with good sleep quality before TURP surgery. 19 patients had good sleep quality after TURP surgery, of which 12 patients had improved sleep quality and 11 others had poor persistent sleep quality (Table 1).

Table 1. Baseline Characteristics IPSS Score and PSQI Score

Before Operation After operation




\section{SIS SRIWIJAYA JOURNAB OFEURGERY}

\begin{tabular}{ccccc}
\hline IPSS Category & Frequency (n) & Percentage (\%) & Frequency (n) & Percentage (\%) \\
\hline Mild & 2 & $6,7 \%$ & 17 & $57,7 \%$ \\
Moderate & 10 & $33,3 \%$ & 12 & $40,0 \%$ \\
Severe & 18 & $60,0 \%$ & 1 & $3,3 \%$ \\
Total & 30 & $100 \%$ & 30 & $100 \%$ \\
& & & & \\
PSQI Category & & & 19 & $63,3 \%$ \\
\hline Good & 7 & $23,3 \%$ & 11 & $36,7 \%$ \\
Poor & 23 & $76,7 \%$ & 30 & $100 \%$ \\
Total & 30 & $100 \%$ & & \\
\hline
\end{tabular}

TURP is effective against decreasing the IPSS score globally with a $\mathrm{P}$ value of 0,000 . The IPSS points that are most influenced by TURP are the symptoms of voiding (weak jets). IPSS points that are least affected by TURP are symptoms of storage (nocturia). TURP is effective against decreasing PSQI scores globally with a $\mathrm{P}$ value of 0,000 . The PSQI point that is most influenced by TURP is the duration of sleep. The PSQI point that is least affected by TURP is the use of sleeping pills (table 2).

Table 2. Efficacy of TURP on IPSS and PSQI Scores

\begin{tabular}{ccccc}
\hline \multirow{2}{*}{ Variable } & \multicolumn{2}{c}{ TURP } & Affence & P value \\
\cline { 2 - 4 } & Before & After & $\begin{array}{c}\text { Difference } \\
\text { in change }\end{array}$ & \\
\hline IPSS & $\pm 21,80$ & $\pm 7,67$ & 14,13 & 0,000 \\
Weak jet & $\pm 3,00$ & $\pm 0,40$ & 2,60 & 0,000 \\
Unsatisfied urination & $\pm 3,56$ & $\pm 1,06$ & 2,50 & 0.000 \\
Interrupted urination & $\pm 2,96$ & $\pm 0,46$ & 2,50 & 0,000 \\
Straining & $\pm 2,60$ & $\pm 0,43$ & 2,17 & 0,000 \\
Urination every 2 hours & $\pm 3,26$ & $\pm 1,26$ & 2,00 & 0,000 \\
Can't hold urine & $\pm 3,26$ & $\pm 1,63$ & 1,63 & 0,003 \\
Nocturia & $\pm 3,46$ & $\pm 2,40$ & 1,06 & 0,003
\end{tabular}




\begin{tabular}{ccccc}
\hline PSQI & $\pm 9,36$ & $\pm 5,03$ & 4,33 & 0,000 \\
Sleep duration & $\pm 2,13$ & $\pm 1,30$ & 0,83 & 0,000 \\
Sleep disorder & $\pm 1,70$ & $\pm 1,06$ & 0,63 & 0,000 \\
Sleep Quality (subjective) & $\pm 1,33$ & $\pm 0,93$ & 0,40 & 0.001 \\
Social dysfunction in daytime & $\pm 0,70$ & $\pm 0,10$ & 0,60 & 0,002 \\
Sleep efficiency & $\pm 1,70$ & $\pm 0,90$ & 0,80 & 0,014 \\
Sleep latency & $\pm 1,70$ & $\pm 1,03$ & 0,66 & 0,014 \\
Taking sleep medication & $\pm 0,10$ & $\pm 0,03$ & 0,81 & 0,423
\end{tabular}

Pair t test, $\mathrm{P}=0,05$

\section{Discussion}

Sleep quality is one's satisfaction with sleep, so someone does not show feelings of fatigue, and easily aroused restless, lethargic and apathetic, blackness around the eyes, swollen eyelids, red conjunctiva, sore eyes, fragmented attention, headaches and often yawn or get sleepy. Sleep quality, according to American Psychiatric Association (2000), is defined as a complex phenomenon involving several dimensions. Sleep quality includes quantitative and qualitative aspects of sleep, such as length of sleep, time needed to be able to fall asleep, frequency of awakening and subjective aspects such as depth and severity of sleep ${ }^{16}$.

There are many factors that affect the quality and quantity of sleep. Often a single factor is not the only cause for sleep problems. Physiological, psychological, and environmental factors often change the quality and quantity of sleep. According to Schweitzer sleeping pills can change sleep patterns and reduce alertness during the day, which then becomes a problem for individuals. Medications prescribed for sleep often cause more problems than benefits. As for some drugs and substances that can cause sleep disorders include alcohol, anorexia, anticholinergic drugs, anticonvulsants (lamotrigine and fenitoin), antidepressants (bupropion, fluoxetine, phenelzine, 


\section{STS SRIWIJAYAJOURNAB OFEURGERY}

protriptyline, tranylcypromine, venlafaxine), antihypertension (daunorubicinelone, gonorrhea, gonorrhea, germ, leuprolide), antiparkinson ${ }^{17}$.

A person's routine can affect sleep patterns. An individual who works in rotation (for example, 2 weeks of daytime followed by 1 week of the night) often has difficulty adjusting changes in sleep schedules. Other changes in routines that disrupt sleep patterns include doing unusual heavy work, engaging in social activities until late at night, and changing dinner time. Psychiatric disorders and emotional stress also relate to mood disorders, anxiety disorders, panic disorders, post-traumatic stress disorder, psychosis, eating disorders, alcoholism, somatoform disorder, and personality disorders. Worry over personal problems or situations often disturbs sleep. Medical conditions that cause sleep disorders include respiratory disorders: obstructive sleep apnea, central sleep apnea, sleep-related asthma, chronic obstructive pulmonary disease, and central alveolar hypoventilation syndrome, heart disorders: nocturnal angina and congestive heart failure, pain syndrome: osteoarthritis, rheumatoid arthritis, and fibromyalgia, gastrointestinal disorders: sleep-related abnormal swallowing syndrome, sleep-related gastroesophageal reflux, and peptic ulcer disease, dermatological disorders: pruritus, cancer and AIDS ${ }^{18-23}$.

The quality of sleep itself is affected by many factors, namely physiological, psychological and environmental factors. This study produced different results from the Naoki Wada study because of differences in psychological conditions, lifestyle, stress levels and sociodemographic, because it was carried out in two different countries with different population populations. Naoki Wada's research was conducted in Japan while the research was conducted in Indonesia

According to the results of Kawamoto et al study, as many as $38.1 \%$ of the elderly population in Japan experience depression (including this is the level of mild depression as well) based on the Zung Self-rating Depressive Scale. According to the Tsuruhei Sukegawa study, $37.3 \%$ (755 of the 2023 study samples) in elderly people in Japan with an average age of 74.2 had sleep disorders with a PSQI score of $\geq 6$, and $31.3 \%$ of the study sample had depression based on scores Geriatric Depression Scale, where sleep disturbances in depressed parents are more common than those of depressed elderly groups. From this study it can be concluded that sleep disturbance in the elderly population in Japan is influenced by the high level of depression that occurs in older people in this country. From a survey conducted by the Ministry of Health Japan in 2000, it was found that one in three parents in Japan experience insomnia, which is affected by 


\section{STS SRIWIJAYAJOURNAB OFEURGERY}

mental and physical health disorders. From Yuko Ito's research from 1996 to 1997 that examined sleep disorders and their correlation with parents in Japan, it was found that sleep disturbance was influenced by low levels of education, work fatigue, higher BMI, irregular sleep time, use of sleeping pills, levels of depression height, cardiovascular disease, joint arthritis and prostatic hypertrophy. The situation that occurs is that there are many sleep disturbance conditions in the elderly population in Japan and this condition affects the differences in the results of this study with Naoki Wada regarding the effectiveness of TURP on the sleep quality of BPH patients. ${ }^{24-25}$

In this study, all IPSS points (7 points) all improved. From the 7 IPSS points, it was found that the symptoms of LUTS that were most influenced by TURP were voiding symptoms (weak beams) with a value of \pm 3.00 before surgery and dropped to \pm 0.40 (difference in change of 2.60) and $\mathrm{p}$ value of 0,000 . This is in accordance with Luitel Gupat examining the results of post TURP surgery after 3 months showing a significant decrease in IPSS scores, with voiding symptoms that are more improved than storage symptoms. While the IPSS points that are least affected by TURP surgery are nocturia symptoms, because although IPSS values overall experience significant improvements in patients, the nocturia points do not significantly improve the quantity, this is in line with research from Naoki Wada which says that nocturia is a one of the most disturbing symptoms of LUTS for patients and the most difficult to treat, because the disease that causes nocturia varies greatly from urological conditions to non-urological conditions. From the study of Yoshimura et al, it was found that 118 patients with nocturia before TURP surgery and after surgery 91 patients continued to experience nocturia ${ }^{26-28}$.

The International Continence Society (ICS) defines nocturia as a complaint whereby one must wake up at night once or more to urinate. The pathophysiology of nocturia is multifactorial and is complex and the cause is unclear in some patients. This nocturia condition often occurs in older people and its frequency increases with increasing age, with the greatest influence on the quality of individual sleep. Sleep disorders can cause drowsiness and fatigue during the day, changes in mood and cognitive dysfunction with lack of concentration. In BPH, nocturia is one of the disorders of LUTS, namely the storage function. In this BPH a bladder outlet obstruction occurs, where the obstruction causes changes in the function of the detrusor muscle accompanied by changes in the function of the bladder and nervous system, causing symptoms of storage 


\section{STS SRIWIJAYAJOURNAB OFEURGERY}

(frequency, urgency and nocturia). If after TURP surgery the symptoms of nocturia do not improve, possibly because hyperactivity of the detrusor muscle still occurs. ${ }^{29}$

According to Hong J Lee's research, the percentage of nocturia is $16 \%$ in men aged $40-49$, $60 \%$ at age $70-79 \%$ and is mostly caused by BPH. There were no significant differences in patients with nocturia in age, prostate volume, PSA, Qmax and PVR between patients with or without nocturia. The total IPSS score and QOL index of patients with nocturia are higher than patients without nocturia. Patients with nocturia have a higher PSQI and a percentage of sleep disorders. Nocturia has a higher impact in LUTS patients. Jensen et al reported that as many as $25 \%$ of the falls experienced by parents at night and as many as $25 \%$ caused by patients waking up to urinate According to the research of Yoong et al, there are many conditions that contribute to nocturia for example diabetes, primary polydipsia, hypercalcemia, daytime fluid retention, venous insufficiency, hypoalbuminemia, diuretic therapy, congestive heart failure, kidney disease, neurological dysfunction and sleep apnea, some of which have been excluded in this study. In the study of Seung Whan et al mentioned that patients with nocturia had higher PSQI values ( $8.5 \pm$ $0.4)$ compared to patients without nocturia $(4.82 \pm 0.4)(\mathrm{p}<0.01)$. From this it follows that nocturia is very influential on sleep quality ${ }^{30}$.

Based on the results of this study also, it was found that BPH patients who still have symptoms of nocturia after TURP surgery have better sleep quality than before surgery. Although this symptom of nocturia is the LUTS symptom that is least affected by TURP, but when compared to the average nocturia symptoms before and after this TURP from \pm 3.46 to \pm 2.40 with a $\mathrm{P}$ value of 0.003 , it can be concluded that TURP is effective against decreasing frequency of nocturia. Although the symptoms of nocturia do not completely disappear in patients, in terms of frequency there is a significant decrease. The decrease in the frequency of nocturia itself has a big influence on the PSQI score, especially point no. 3 which is the duration of sleep in which some patients experience an improvement in the duration of the average length of sleep after TURP surgery. This is consistent with Sonia A et al's study where the result is a decrease in the frequency of nocturia followed by a significant increase in the average sleep hours ${ }^{31}$.

Of the two main points of this study, namely sleep quality is the main result of the study assessed by the PSQI score and LUTS symptoms which are additional results assessed by IPSS it can be concluded that the improvement of the PSQI value is significant and in line with the 


\section{SSS SRIWIJAYA JOURNAL OFSURGERY}

improvement of the IPSS value and frequency of nocturia in patients BPH before and after TURP surgery.

\section{Conclusion}

There were significant differences in the sleep quality of BPH patients before and after TURP surgery, namely that there was a significant improvement in sleep quality assessed by PSQI scores before and after TURP surgery.

\section{References}

1. Naoki W, Atsushi N, Kyokushin H, Masaki W, Masafumi K, Seiji M, Hiroaki O, Makoto F, Hidehiro K. Nocturia and sleep quality after transurethral resection of the postat. International Journal of Urology (2014) 21, 81-85

2. Seong Beom, Chen Z, Jong K. The effect of Transurethral Resection of the Prosat on Erectile Function in patient with Benign Prostatic Hyperplasia. www. kjurology.org DOI:10.4111/kju.2010.51.8.557.

3. Quinte Health care. Transurethral Resection of Prostate (TURP). Departement of Urology

4. Nakagawa H, Niu K, Hozawa A et al. Impact of Nocturia on Bone fracture and mortality in older individuals: a Japanese longitudinal cohort study. J.Urol. 2010; 184: 1413-18

5. Marklund H, Spangberg A, Edell-Gustafsson U. Sleep and health-related quality of life in patient with lower urinary tract symptoms suggetive of benign prostatic obstruction compared to the general population and patients with inguinal hernia. Scand. J. Urol. Nephrol. 2010; 44: 304-14

6. Serge P Marincovic, Managing Nocturia, Clinical Review. BMJ Volume 328 May ${ }^{1 s t} 2004$

7. Jensen J, Lundin O, Nyberg L, Gustafson Y, Falls Among Frail Older People in Residential Care. Scand J Public Health 2002; 30910 : 54-61

8. I-Huang S, Chia C, The Effect of Nocturia on Sleep Quality and Daytime Function in Patient with Lower Urinary Tract Symptoms : A Cross Sectional Study. Clinical Interventions in Aging2016 : 11 879-885

9. Hong J, Seung W, Jin A. Strong Impact of Nocturia on Sleep Quality in Patients with Lower Urinary Tract Symptoms. World J Mens Health 2012 August 30(2) : 123-130

10. Chie Matsushita, kazumasa Torimoto, Linkage of Lower Urinary Track Symptoms to Sleep Quality in Elderly Men With Nocturia: A Community Based Study Using Home Measured Electroencephalogram Data. www.jurology.com. Juli $20^{\text {th }}, 2016$ 


\section{SSS SRIWIJAYA JOURNABOPSURGERУ}

11. Buysse DJ, Monk T, Berman S, Kupfer D, The Pittsburgh Sleep Quality Indeks (PSQI) A New Insrument for Psychiatic Research and Practice. Psychiatry Research 28(2) 193-213

12. Amber L Bush, Maria E.A. The pittsburgh Sleep Quality in Older Primary Care Patient with Generalized Anxiety Disorder : Pyschometrics and Outcome Following Cognitive Behavioral Therapy. Psychiatry Res 2012. August $30: 199(1): 24-30$

13. Ikbal Z. Uji validitas dan Reabilitas Instrumen Pittsburg Sleep Quality Indeks Versi Bahasa Indonesia. Universitas Indonesia. Jakarta 2015

14. Shunichi Namiki, Shigeto Ishidaya. Natural History of Voiding Function After Radical Retropubic Prostatectomy. urology elsevier inc 200668 : 142-147

15. Luitel BR, Gupta DK. Change in Storage Symptoms after Transuretral Resection of Prostate : A Prospective Observasional Study. JSSN 204 : 17(1)

16. Roehrborn CG \& Connell MJ,. Etiology, Patophysiology and Natural History of Benign Prostatic Hyperplasia. In the : Whals PC, Retik AB, Eds: Campbels Urology $9^{\text {th }}$. Philadelphia: 2002 WB Saunders; 1297-1330

17. Connell MJ, Abrahams P. Evaluation and Treatment of LUTS in Older Men. Male urinary tract dysfunction evaluation and management. 2009.4,342-349

18. Presti JC, Neoplasms of the Prostate Gland. Smith's General Urology. $16^{\text {th }}$ ed New York : Lange Medical Books/Mc Graw - Hill 2004 ; p.367-385

19. Claus G, Roehrborn, John D, Connell MJ,. Benign Prostatic Hyperplasia: Etiology, Patophysiology, Epidemiology, and Natural History. Walsh PC: Campbell's Urology, $10^{\text {th }}$ 2007 ed: chapter 86

20. Greene KL, Albertsen PC, Babain RJ, Cartet HB, Gann PH, Han M, Kuban DA, Sartor AO, Stanford JL, Zietman A, Carroll P; American Urological Association. Prostat specific antigen best practice statement: 2009 update. J Urol. 2013 Jan;189(1 Suppl): S2 S11. doi: 10.1016/j.juro.2012.11.014

21. Connell MJ,. Combination Theraphy Significantly Delays Progression of Benign Prostatic Hyperplasia. 2005 . www.nyp.org/news/hospital.

22. Lee C \& Cockett A, Regulation of Prostate Growth. In the : Chatelain C, Denis L, et al : Benign Prostate Hyperplasia, 2010.5 ${ }^{\text {th }}: 81-99$ 


\section{SSS SRIWIJAYAJOURNABOPSURGERY}

23. Wein AJ \& Rovner ES,.Benign Prostatic Hyperplasia. In the : Hanno PM, Malkowicz SB, et al: Clinical Manual of Urology, $20013^{\text {rd }}, 437-470$

24. Taher A,. Erectile Dysfunction After Transurethral Resection of the Prostate, Incidence and Risk Factors. 2004World Journal Urology,22:457-460

25. Foster HE \& Jacobs MB, 2004. Transuretrhal Resection of the Prostate. In: Management of Benign Prostatic Hypertrophy. Northwestern University Feinberg School of Medicine, Chicago ,IL;vol: 10,chapter 11, 163-193

26. Poulakis V, Ferakis N, Witzsch U, et al, 2006. Erectile Dysfunction After Transurethral Prostatectomy for Lower Urinary Tract Symptoms : Results from A Center with Over 500 Patients. Asian J Androl; 8:69-74

27. Richard A, Chaidir A. Validation of Indonesian Version of IPSS. Indonesian Journal of Urology. 2014 Vol 21. no 1

28. Ganong, W. F. (2003). Buku ajar fisiologi kedokteran. edisi 20. 186 - 195. Jakarta: EGC

29. Potter \& Perry. (2013). Fundamental of Nursing. 8th edition. 939 - 946. Elsevier

30. Choppra, D. (2003). Tidur Nyenyak, Mengapa Tidak? Ucapkan Selamat Tinggal pada Insomnia. Yogyakarta: Ikon Teralitera.

31. Colten, H. R., \& Bruce M. A. Sleep disorders and sleep deprivation: an unmet public health problem. Committee on Sleep Medicine and Research. Washington,DC: The National Academies Press. 2006. 